\title{
Simultaneous Analysis of Glucosinolates and Isothiocyanates by Reversed-Phase Ultra-High-Performance Liquid Chromatography- Electron Spray lonization-Tandem Mass Spectrometry
}

Silvia Andini, Carla Araya-Cloutier, Mark Sanders, and Jean-Paul Vincken*

Cite This: J. Agric. Food Chem. 2020, 68, 3121-3131

Read Online

ACCESS

Џlll Metrics \& More

回国 Article Recommendations

Supporting Information

ABSTRACT: A new method to simultaneously analyze various glucosinolates (GSLs) and isothiocyanates (ITCs) by reversedphase ultra-high-performance liquid chromatography-electron spray ionization-tandem mass spectrometry has been developed and validated for 14 GSLs and 15 ITCs. It involved derivatization of ITCs with $N$-acetyl-L-cysteine (NAC). The limits of detection were 0.4-1.6 $\mu \mathrm{M}$ for GSLs and 0.9-2.6 $\mu \mathrm{M}$ for NAC-ITCs. The analysis of Sinapis alba, Brassica napus, and Brassica juncea extracts spiked with 14 GSLs and 15 ITCs indicated that the method generally had good intraday ( $\leq 10 \%$ RSD) and interday precisions ( $\leq 16 \%$ RSD). Recovery of the method was unaffected by the extracts and within $71-110 \%$ for GSLs and $66-122 \%$ for NAC-ITCs. The method was able to monitor the enzymatic hydrolysis of standard GSLs to ITCs in mixtures. Furthermore, GSLs and ITCs were simultaneously determined in Brassicaceae plant extracts before and after myrosinase treatment. This method can be applied to further investigate the enzymatic conversion of GSLs to ITCs in complex mixtures.

KEYWORDS: LC-MS analysis, glucosinolate breakdown product, validation, mustard, dithiocarbamate, thioglucosidase

\section{INTRODUCTION}

Glucosinolates (GSLs) are widely distributed in all plant tissues within the Brassicaceae family. They play an important role to defend the plants against pathogen and insect attacks. ${ }^{1}$ This defense system is assisted by myrosinase. Just like GSLs, myrosinase is found in all tissues of Brassicaceae plants, but it is located in different cells. ${ }^{2}$ Myrosinase gets in contact with GSLs when the plant tissues are damaged. ${ }^{3}$ In an environment

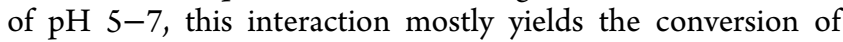
GSLs into microbiologically active isothiocyanates (ITCs) (Figure 1A). ${ }^{4-6}$ Previous studies reported that depending on the structure, ITCs could inhibit the growth of fungi and bacteria pathogenic to plants ${ }^{7,8}$ and humans. ${ }^{9-11}$ This underlines the potential of ITCs as a new class of plantderived antimicrobial compounds.

The chemical diversity of GSLs, imparted by various side chains (R-group), determines which ITCs can be formed. ${ }^{12}$ In general, the R-group can be an aliphatic, benzenic, or indolic group. Based on the type of R-group, GSLs and ITCs can be classified at least into eight and seven subclasses, respectively (Table 1). ITCs have one subclass less, because those with an indole R-group are unstable. ${ }^{13}$ Although ITCs share the Rgroup of GSLs, ITCs have a completely different core structure than GSLs (Figure 1A). Consequently, ITCs and GSLs have different volatility and ionization ability, making simultaneous analysis difficult. Therefore, GSLs and ITCs have frequently been analyzed separately by mainly liquid chromatography (LC) and gas chromatography (GC). ${ }^{14}$

GSLs are highly polar because of a thioglucosyl group $(-\mathrm{SGlc})$ and a strong acid residue $\left(\mathrm{SO}_{4}{ }^{2-}\right)$. The latter causes GSLs to be spontaneously ionized as an anion. Removal of the strong acid residue, that is, desulfation, is often required in various LC-mass spectrometry (MS) methods. ${ }^{15-19}$ However, this step could result in incomplete desulfation, selfdimerization, and self-degradation. ${ }^{20-22}$ LC-MS methods for direct quantitative analysis of individual intact GSLs without desulfation were developed. ${ }^{23-26}$ However, efficient LC-MS analysis of intact GSLs was historically challenging ${ }^{27}$ and most methods included only few GSLs and do not cover the analysis of ITCs.

The volatility of ITCs makes GC a convenient technique for ITC analysis. However, several ITCs were thermally unstable. Allyl ITC (AITC) and 4-(methylsulfinyl)butyl ITC (4MSITC) were transformed into allyl thiocyanate and 3-butenyl ITC (BuITC), respectively, in the GC injection port. ${ }^{28,29}$ LC analysis of ITCs was developed previously employing derivatization with thiol compounds, which can overcome the limitation of GC analysis. ${ }^{30-32}$ In particular, Pilipczuk et al. ${ }^{31}$ successfully developed an LC-MS method to quantify various individual ITCs derivatized with $\mathrm{N}$-acetyl-L-cysteine (NAC), a safe derivatization reagent. This derivatization allowed the ionization of ITCs, while keeping their R-groups intact (Figure 1B). However, this LC-MS method did not cover the analysis of GSLs.

Tsao et al. ${ }^{33}$ developed a method to simultaneously analyze allyl GSL (AGSL) and AITC by using high-performance liquid

Received: December 13, 2019

Revised: February 10, 2020

Accepted: February 13, 2020

Published: February 13, 2020 
A

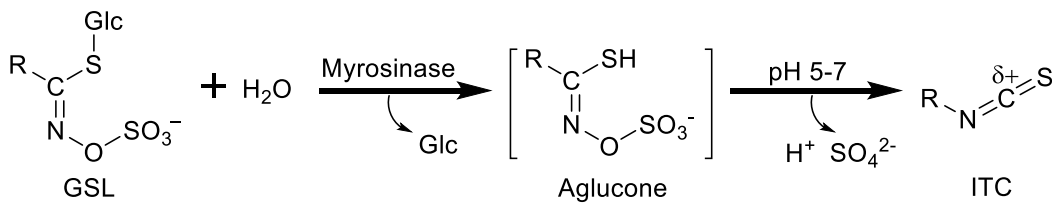

B

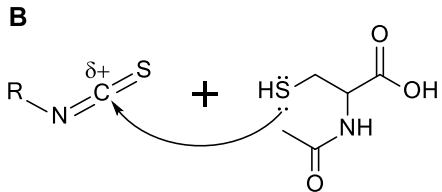

ITC

NAC

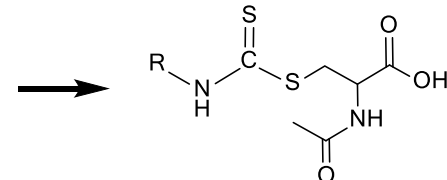

NAC-ITC

Figure 1. Conversion of GSL to ITC by myrosinase at $\mathrm{pH}$ 5-7 (A) and derivatization reaction of ITC with NAC (B). Carbon atom in the ITC functional group is electrophilic.

chromatography (HPLC) with UV detection at $228 \mathrm{~nm}$ for AGSL and $242 \mathrm{~nm}$ for AITC. This method is, however, not suitable for analyzing GSLs in a mixture because many compounds absorb at $228 \mathrm{~nm}$. Franco et al. ${ }^{34}$ developed a simultaneous method for specific pairs of GSLs/ITCs, without precolumn derivatization, by using reversed-phase (RP) HPLC-electron spray ionization (ESI)-tandem mass spectrometry (MS/MS). This method was applicable to analyze the compounds in complex matrices. However, it was only evaluated for 4-(methylsulfinyl)butyl GSL/ITC and 4(methylthio)butyl GSL/ITC. Another HPLC-based method developed to simultaneously analyze GSLs and ITCs was also evaluated only for few pairs, for example, AGSL/ITC, phenyl GSL/ITC, and benzyl GSL/ITC. ${ }^{35}$ Moreover, one study described the simultaneous analysis of only few pairs of GSLs/ ITCs by another separation technique, namely, capillary electrophoresis micellar electrokinetic chromatography (CEMEKC) ${ }^{36}$ Altogether, to date there is no method which has been evaluated to analyze many more GSLs and ITCs in complex mixtures in a single analytical run.

In this study, we aimed at developing and validating an LCMS method which can simultaneously analyze various GSLs and ITCs in complex mixtures. Derivatization of ITCs with NAC was included in the method to enhance the ionization ability of ITCs. ${ }^{31}$ The method would enable the monitoring of the in vitro enzymatic hydrolysis of GSLs and the formation of ITCs in standard mixtures and plant extracts upon myrosinase treatment.

\section{MATERIALS AND METHODS}

Standard Compounds and Other Chemicals. Authentic standards of 14 GSLs listed in Table 1 were purchased from PhytoLab GmbH \& Co (Vestenbergsgreuth, Germany). Authentic standards of nine ITCs (with peak numbers in boldface according to Table 1): 3-(methylsulfinyl)propyl ITC (3-MSITC, I1), 4(methylsulfinyl)butyl ITC (4-MSITC, I2), 6-(methylsulfinyl)hexyl ITC (6-MSITC, I3), 9-(methylsulfinyl)nonyl ITC (9-MSITC, I4), 4(methylsulfinyl)-3-butenyl ITC (4-MS-3-en-ITC, I5), 3(methylsulfonyl)propyl ITC (3-MSoITC, I6), 3-(methylthio)propyl ITC (3-MTITC, I7), 4-(methylthio)butyl ITC (4-MTITC, I8), and 5-(methylthio)pentyl ITC (5-MTITC, I9) were purchased from Abcam (Cambridge, UK). Authentic standards of the other six ITCs: propyl ITC (PITC, I10), AITC (I11), 3-butenyl ITC (BuITC, I12), 4-pentenyl ITC (PeITC, I14), benzyl ITC (BITC, I15), and phenethyl ITC (PhEITC, I17) were purchased from Sigma-Aldrich (St. Louis, MO, U.S.A.) or Merck (Darmstadt, Germany). NAC-4MSITC of an authentic standard was purchased from Cayman Chemical (Ann Arbor, MI, U.S.A.). NAC-BITC and NAC-PhEITC of an authentic standard were purchased from Abcam (Cambridge, $\mathrm{UK})$.

NAC, $\mathrm{NaOH}, \mathrm{KH}_{2} \mathrm{PO}_{4}$, myrosinase, $n$-hexane, and tert-butanol were purchased from Sigma-Aldrich (St. Louis, MO, U.S.A.) or Merck (Darmstadt, Germany). Dimethyl sulfoxide (DMSO) was purchased from Duchefa Biochemie (Haarlem, The Netherlands). Isopropanol (IPA) (ULC/MS grade), acetonitrile (ACN) acidified with $0.1 \%$ (v/ v) formic acid (FA) (ULC/MS grade), water acidified with $0.1 \%$ (v/ v) FA (ULC/MS grade), and methanol $(\mathrm{MeOH})$ (ULC/MS grade) were purchased from Biosolve BV (Valkenswaard, The Netherlands). High-purity water was produced in-house using a Milli-Q A10 Gradient system (18.2 M $\Omega \cdot \mathrm{cm}, 3 \mathrm{ppb}$ TOC) (Merck Millipore, Darmstadt, Germany).

Plant Materials. Seeds of Sinapis alba (yellow mustard "Emergo", 393,810), Brassica napus ("Helga", 392,600), and Brassica juncea var. rugosa rugosa (Chinese mustard/amsoi, 160,400) were purchased from Vreeken's Zaden (Dordrecht, The Netherlands). B. juncea var. rugosa rugosa is referred to as $B$. juncea in the following text.

Preparation of Stock Solutions of GSLs, ITCs, and NAC. Stock solutions $(5 \mathrm{mM})$ of GSLs and ITCs were prepared in phosphate buffer $\mathrm{pH} 7(0.1 \mathrm{M})$ and in IPA, respectively. All standard GSLs and ITCs were weighed on a Mettler XP6 microbalance (Mettler-Toledo International Inc., U.S.A.). Stock solutions were kept at $-20{ }^{\circ} \mathrm{C}$ before use. A stock solution of NAC $(100 \mathrm{mM})$ was freshly prepared in phosphate buffer, $\mathrm{pH} 7.0(0.1 \mathrm{M})$.

Extraction of GSLs from Brassicaceae Seeds. Ground seeds of S. alba, B. napus, and B. juncea were extracted in a SpeedExtractor E916 (Büchi, Flawil, Switzerland) by using absolute methanol at $65^{\circ} \mathrm{C}$ as described in a previous study. ${ }^{37}$ Afterward, the extract was evaporated under reduced pressure (Syncore Polyvap, Büchi), resolubilized in tert-butanol, and freeze-dried. The dried extracts were stored at $-20{ }^{\circ} \mathrm{C}$.

Derivatization of ITCs with NAC. Four different experiments were carried out in which NAC was combined with (i) standard mixtures of 14 GSLs and 15 ITCs, (ii) plant extracts spiked with mixtures of 14 GSLs and 15 ITCs, (iii) a mixture of standard GSLs and myrosinase, and (iv) mixtures of plant extracts and myrosinase.

Derivatization experiments of the mixtures of standard ITCs and GSLs were performed for making calibration curves of each ITC and GSL, to evaluate the linearity range, to determine limit of detection (LOD) and limit of quantification (LOQ), and to quantify GSLs and ITCs in the samples. NAC was added into the mixtures of 14 GSLs and 15 ITCs. The final molar concentration of NAC was five times higher than that of total ITCs. IPA was added to the mixtures to a concentration of $25 \%(\mathrm{v} / \mathrm{v})$, in which both GSLs and ITCs were soluble (Figure S1). During preparation, all solutions were kept in an ice bath. All reaction mixtures were incubated at $50{ }^{\circ} \mathrm{C}$ for $2 \mathrm{~h}$ with constant mixing at $900 \mathrm{rpm}$. Then, the samples were chilled and analyzed by RP ultra-high-performance liquid chromatography (UHPLC)-MS. The completeness of the derivatization after $2 \mathrm{~h}$ incubation was established for 4-MSITC, BITC, and PhEITC by 
Table 1. GSLs and ITCs in the Study

\begin{tabular}{|c|c|c|c|c|c|c|}
\hline subclass & $\begin{array}{l}\text { structure of } \\
\text { R-group }\end{array}$ & $\begin{array}{l}\text { (semi)systematic } \\
\text { name of R-group }\end{array}$ & $\begin{array}{l}\text { abbreviation of } \\
\text { GSL or ITC }\end{array}$ & $\begin{array}{l}\text { trivial name of GSL or } \\
\text { ITC }\end{array}$ & $\operatorname{code}^{a}$ & $\begin{array}{l}\text { retention } \\
\text { time (tR, } \\
\text { min) }\end{array}$ \\
\hline \multirow[t]{5}{*}{$\begin{array}{l}\text { aliphatic } \\
\text { (methylsulfinyl)alkyl }\end{array}$} & & $\begin{array}{l}\text { 3- } \\
\text { (methylsulfinyl)propyl }\end{array}$ & $\begin{array}{l}\text { 3-MSGSL } \\
\text { 3-MSITC }\end{array}$ & $\begin{array}{l}\text { glucoiberin } \\
\text { iberin }\end{array}$ & $\begin{array}{l}\text { G1* } \\
\text { I }^{*}\end{array}$ & $\begin{array}{l}1.99 \\
17.53\end{array}$ \\
\hline & & 4-(methylsulfinyl)butyl & $\begin{array}{l}\text { 4-MSGSL } \\
\text { 4-MSITC }\end{array}$ & $\begin{array}{l}\text { glucoraphanin } \\
\text { sulforaphane }\end{array}$ & $\begin{array}{l}\mathbf{G 2}^{*} \\
12^{*}\end{array}$ & $\begin{array}{l}3.11 \\
19.88\end{array}$ \\
\hline & O & 5-(methylsulfinyl)pentyl & $\begin{array}{l}\text { 5-MSGSL } \\
\text { 5-MSITC }\end{array}$ & $\begin{array}{l}\text { glucoalyssin } \\
\text { alyssin }\end{array}$ & $\begin{array}{l}\text { G19 } \\
119\end{array}$ & $\begin{array}{l}4.37 \\
23.44\end{array}$ \\
\hline & & 6-(methylsulfinyl)hexyl & $\begin{array}{l}\text { n.a. } \\
\text { 6-MSITC }\end{array}$ & $\begin{array}{l}\text { n.a. } \\
\text { hesperin }\end{array}$ & $13^{*}$ & - \\
\hline & 0 & 9-(methylsulfinyl)nonyl & $\begin{array}{l}\text { n.a. } \\
\text { 9-MSITC }\end{array}$ & $\begin{array}{l}\text { n.a. } \\
\text { 9-(methylsulfinyl)nonyl } \\
\text { ITC }\end{array}$ & $\begin{array}{l}\text { n.a. } \\
14^{*}\end{array}$ & $-\overline{36.53}$ \\
\hline (methylsulfinyl)alkenyl & & $\begin{array}{l}\text { 4-(methylsulfinyl)-3- } \\
\text { butenyl }\end{array}$ & $\begin{array}{l}\text { 4-MS-3-en-GSL } \\
\text { 4-MS-3-en-ITC }\end{array}$ & $\begin{array}{l}\text { glucoraphenin } \\
\text { sulforaphene }\end{array}$ & $\begin{array}{l}\mathbf{G}^{*} \\
15^{*}\end{array}$ & $\begin{array}{l}3.36 \\
20.44\end{array}$ \\
\hline (methylsulfonyl)alkyl & & $\begin{array}{l}\text { 3- } \\
\text { (methylsulfonyl)propyl }\end{array}$ & $\begin{array}{l}\text { 3-MSoGSL } \\
\text { 3-MSolTC }\end{array}$ & $\begin{array}{l}\text { glucocheirolin } \\
\text { cheirolin }\end{array}$ & $\begin{array}{l}G 6^{*} \\
16^{*}\end{array}$ & $\begin{array}{l}2.33 \\
19.60\end{array}$ \\
\hline \multirow[t]{2}{*}{ (methylthio)alkyl } & & 3-(methylthio)propyl & $\begin{array}{l}\text { 3-MTGSL } \\
\text { 3-MTITC }\end{array}$ & $\begin{array}{l}\text { glucoibervirin } \\
\text { ibervirin }\end{array}$ & $\begin{array}{l}\text { G7 } \\
17^{*}\end{array}$ & $\begin{array}{l}12.60 \\
32.49\end{array}$ \\
\hline & & $\begin{array}{l}\text { 4-(methylthio)butyl } \\
\text { 5-(methylthio)pentyl }\end{array}$ & $\begin{array}{l}\text { 4-MTGSL } \\
\text { 4-MTITC } \\
\text { 5-MTGSL } \\
\text { 5-MTITC }\end{array}$ & $\begin{array}{l}\text { glucoerucin } \\
\text { erucin } \\
\text { glucoberteroin } \\
\text { berteroin }\end{array}$ & $\begin{array}{l}\text { G8* } \\
18^{*} \\
\mathbf{G 9 ^ { * }} \\
19^{*}\end{array}$ & $\begin{array}{l}15.08 \\
35.78 \\
18.73 \\
39.15\end{array}$ \\
\hline alkyl & & propyl & $\begin{array}{l}\text { n.e.c } \\
\text { PITC }\end{array}$ & $\begin{array}{l}\text { n.e. } \\
\text { propyl ITC }\end{array}$ & $110^{*}$ & $-\overline{29.04}$ \\
\hline \multirow[t]{5}{*}{ alkenyl } & & 2-propenyl (= allyl) & $\begin{array}{l}\text { AGSL } \\
\text { AITC }\end{array}$ & $\begin{array}{l}\text { sinigrin } \\
\text { allyl ITC }\end{array}$ & $\begin{array}{l}\text { G11* } \\
111^{*}\end{array}$ & $\begin{array}{l}2.90 \\
25.87\end{array}$ \\
\hline & & 3-butenyl & $\begin{array}{l}\text { BuGSL } \\
\text { BuITC }\end{array}$ & $\begin{array}{l}\text { gluconapin } \\
\text { 3-butenyl ITC }\end{array}$ & $\begin{array}{l}\text { G12* } \\
\mathrm{I12}^{*}\end{array}$ & $\begin{array}{l}7.82 \\
31.66\end{array}$ \\
\hline & & 2-hydroxy-3-butenyl & $\begin{array}{l}\text { 2-OH-BuGSL } \\
\text { n.e. }\end{array}$ & $\begin{array}{l}\text { progoitrin } \\
\text { n.e. }\end{array}$ & $\mathbf{G}^{\mathbf{G}} \mathbf{3}^{*}$ & $\begin{array}{l}2.67 \\
-\end{array}$ \\
\hline & & 4-pentenyl & $\begin{array}{l}\text { PeGSL } \\
\text { PeITC }\end{array}$ & $\begin{array}{l}\text { glucobrassicanapin } \\
\text { 4-pentenyl ITC }\end{array}$ & $\begin{array}{l}\mathrm{G} 14^{*} \\
\mathrm{I14^{* }}\end{array}$ & $\begin{array}{l}14.05 \\
36.04\end{array}$ \\
\hline & & 2-hydroxy-4-penteny| & $\begin{array}{l}\text { 2-OH-PeGSL } \\
\text { n.e. }\end{array}$ & $\begin{array}{l}\text { gluconapoleiferin } \\
\text { n.e. }\end{array}$ & G20 & $\begin{array}{l}9.30 \\
-\end{array}$ \\
\hline \multirow[t]{3}{*}{ benzenic } & & benzyl & $\begin{array}{l}\text { BGSL } \\
\text { BITC }\end{array}$ & $\begin{array}{l}\text { glucotropaeolin } \\
\text { benzyl ITC }\end{array}$ & $\begin{array}{l}\text { G15* } \\
115^{*}\end{array}$ & $\begin{array}{l}14.72 \\
36.53\end{array}$ \\
\hline & & $p$-hydroxybenzyl & $\begin{array}{l}p \text {-OH-BGSL } \\
p \text {-OH-BITC }\end{array}$ & $\begin{array}{l}\text { glucosinalbin } \\
p \text {-hydroxy-benzyl ITC }\end{array}$ & $\begin{array}{l}\text { G16* } \\
116\end{array}$ & $\begin{array}{l}3.83 \\
30.15\end{array}$ \\
\hline & & phenethyl & $\begin{array}{l}\text { PhEGSL } \\
\text { PhEITC }\end{array}$ & $\begin{array}{l}\text { gluconasturtiin } \\
\text { phenethyl ITC }\end{array}$ & $\begin{array}{l}\mathrm{G} 17^{*} \\
117^{*}\end{array}$ & $\begin{array}{l}18.54 \\
39.38\end{array}$ \\
\hline indolic & & indole-3-ylmethyl & MMGSL & $\begin{array}{l}\text { glucobrassicin } \\
\text { n.e. }\end{array}$ & $\begin{array}{l}\text { G18* } \\
-\end{array}$ & $\begin{array}{l}16.59 \\
-\end{array}$ \\
\hline
\end{tabular}

${ }^{a}$ Codes in the chromatograms for GSLs start with G and for ITCs (analyzed as NAC-ITCs) start with I. Asterisk (*) is to indicate that the authentic standard was available in the study. ${ }^{b}$ n.a. refers to GSLs or ITCs which were not available in this study. ${ }^{c}$ n.e. refers to GSLs or ITCs which have never been reported.

comparing the amount of NAC derivatives, which were formed, to that of their respective standards (NAC-4-MSITC, NAC-BITC, and NAC-PhEITC) (Figure S2). Based on this, it was assumed that the derivatization of the 12 other ITCs was also completed in $2 \mathrm{~h}$.

Derivatization experiments of extracts spiked with mixtures of 14 GSLs and 15 ITCs were performed for evaluating the applicability of the method for analyzing GSLs and NAC-ITCs in extracts, in terms of precision and recovery. The approach described earlier was applied in which a mixture of 14 GSLs and 15 ITCs was added to $S$. alba, $B$. napus, and $B$. juncea seed extracts. Two final concentrations at the mid-levels of calibration range for each GSL and ITC were applied, that is, 10 and $30 \mu \mathrm{M}$. Therefore, the final concentrations of NAC were $0.75 \mathrm{mM}(5 \times 10 \mu \mathrm{M} \times 15$ ITCs $)$ and $2.25 \mathrm{mM}(5 \times 30 \mu \mathrm{M} \times$ 15 ITCs), respectively. The final concentration of the extracts was 5 $\mathrm{mg} / \mathrm{mL}$ prepared from the dried extracts solubilized in DMSO (final concentration of 5\%) in phosphate buffer, $\mathrm{pH}$ 7.0. The mixtures were conditioned in phosphate buffer, $\mathrm{pH} 7.0$, and incubated for $2 \mathrm{~h}$ at 50 ${ }^{\circ} \mathrm{C}$ with a constant mixing at $900 \mathrm{rpm}$. Dilution of extracts in phosphate buffer, $\mathrm{pH}$ 7.0, was made for analyzing GSLs and ITCs present at a higher concentration than $60 \mu \mathrm{M}$ (the upper limit of the calibration range).

Derivatization experiments of a mixture of standard GSLs and myrosinase, that is, simultaneous enzymatic hydrolysis of GSLs and derivatization of ITCs, were performed for testing the applicability of the method to monitor the hydrolysis of GSLs and the formation of ITCs. The mixture of 14 standard GSLs (30 $\mu \mathrm{M}$ each) and myrosinase $(0.01 \mathrm{U} / \mathrm{mL}, 1$ unit of enzymatic activity was defined as the amount of enzyme that releases $1 \mu \mathrm{mol}$ glucose per min with AGSL as the substrate, at $\mathrm{pH} 6.0$ and $25{ }^{\circ} \mathrm{C}$ ) were incubated in phosphate buffer, pH $7.0(0.1 \mathrm{M})$ at $50{ }^{\circ} \mathrm{C}$ in the presence of NAC $(2.1 \mathrm{mM})$. GSLs and ITCs were monitored over time until all GSL peaks disappeared, and the intensity of all NAC-ITC peaks did not 
increase anymore, that was up to $4 \mathrm{~h}$. After incubation, IPA was added to a concentration of $25 \%(\mathrm{v} / \mathrm{v})$, the samples were chilled, and analyzed by RP-UHPLC-ESI-MS.

The GSL hydrolysis rates $(\mu \mathrm{M} / \mathrm{h})$ were defined as the decrease of GSL concentration over time and determined as the slope of the plot of GSL concentration $(\mu \mathrm{M})$ versus time (h). The NAC-ITC formation rates $(\mu \mathrm{M} / \mathrm{h})$ were defined as the increase of NAC-ITC concentration over time and determined as the slope of the plot of NAC-ITC concentration $(\mu \mathrm{M})$ versus time $(\mathrm{h})$.

Derivatization experiments of mixtures of Brassicaceae seed extracts and myrosinase were performed with the same incubation as before to test the applicability of the method to analyze GSLs and ITCs in plant extracts upon myrosinase treatment and NAC derivatization. Shortly, the dried extracts were dissolved in DMSO and then 10 times diluted in phosphate buffer, $\mathrm{pH} 7.0(0.1 \mathrm{M})$. Plant extracts $5 \mathrm{mg} / \mathrm{mL}$, myrosinase $0.05 \mathrm{U} / \mathrm{mL}$, and NAC at $5 \times$ estimated concentration of ITCs were incubated at $50{ }^{\circ} \mathrm{C}$ for $4 \mathrm{~h}$, with a final concentration of DMSO of 5\%. Under this condition, all GSL peaks disappeared within $4 \mathrm{~h}$ (data not shown). The concentration of ITCs in B. napus, B. juncea, and $S$. alba seed extracts was estimated from the original GSL concentration analyzed previously. ${ }^{37}$ Afterward, IPA was added to a concentration of $25 \%(\mathrm{v} / \mathrm{v})$. The samples were chilled and analyzed by RP-UHPLC-ESI-MS. When the concentration of GSLs and ITCs exceeded $60 \mu \mathrm{M}$ (the upper limit of the calibration range), they were diluted in phosphate buffer, $\mathrm{pH}$ 7.0.

Simultaneous RP-UHPLC-MS ${ }^{n}$ Analysis of GSLs and NACITCs. Analysis of GSLs and NAC-ITCs was performed on an Accela UHPLC system (Thermo Scientific, San Jose, CA, U.S.A.) equipped with a pump, autosampler, and photodiode array (PDA) detector. An LTQ Velos ESI ion trap mass spectrometer (Thermo Scientific) was coupled to the LC system.

The sample $(1 \mu \mathrm{L})$ was injected onto an Acquity UPLC-BEH shield RP18 column $(2.1 \mathrm{~mm}$ i.d. $\times 150 \mathrm{~mm}, 1.7 \mu \mathrm{m}$ particle size; Waters, Milford, MA, U.S.A.) with an Acquity UPLC BEH shield RP18 VanGuard precolumn $(2.1 \mathrm{~mm}$ i.d. $\times 5 \mathrm{~mm}, 1.7 \mu \mathrm{m}$ particle size; Waters). Water acidified with $0.1 \%(\mathrm{v} / \mathrm{v})$ FA, eluent $\mathrm{A}$, and ACN acidified with $0.1 \%(\mathrm{v} / \mathrm{v})$ FA, eluent $\mathrm{B}$, were used as solvent at a flow rate of $300 \mu \mathrm{L} / \mathrm{min}$. The temperature of the sample tray was controlled at $4{ }^{\circ} \mathrm{C}$ to prevent further reaction. Different column oven temperatures were tested: 25,35 , and $45{ }^{\circ} \mathrm{C}$. The PDA detector was set to monitor absorption at $200-400 \mathrm{~nm}$. The elution gradient used was: $0-6.7 \mathrm{~min}$, isocratic on $0 \%(\mathrm{v} / \mathrm{v}) \mathrm{B} ; 6.7-12.5 \mathrm{~min}$, linear gradient to $8 \% \mathrm{~B}$; $12.5-24.2 \mathrm{~min}$, linear gradient from 8 to $16 \% \mathrm{~B}$; 24.2-41.8 min, linear gradient from 16 to $40 \% \mathrm{~B} ; 41.8-43.5 \mathrm{~min}$, linear gradient from 40 to $100 \%$ B; $43.5-50.5 \mathrm{~min}$, isocratic on $100 \%$ B; 50.5-52 min, linear gradient from 100 to $0 \% \mathrm{~B}$; 52-59 min, isocratic on $0 \% \mathrm{~B}$.

MS analysis was performed on an LTQ Velos equipped with a heated ESI-MS probe coupled to RP-UHPLC. The spectra were acquired in an $\mathrm{m} / z$ (mass to charge ratio) range of 92-1000 $\mathrm{Da}$ in both positive (PI) and negative ionization (NI) modes. The PI mode was used only for identification of NAC-ITCs to complement the data from NI mode. Data-dependent $\mathrm{MS}^{\mathrm{n}}$ analysis was performed on the most intense (product) ion with normalized collision energy of $35 \%$. Nitrogen was used as sheath and auxiliary gas. The ion transfer tube temperature was $300{ }^{\circ} \mathrm{C}$, and the source voltage was $4.0 \mathrm{kV}(\mathrm{PI})$ or $4.5 \mathrm{kV}(\mathrm{NI})$.

The identification and quantification of peaks were performed in Xcalibur (v.2.2, Thermo Scientific). The identification was based on UV and MS spectra. GSLs were detected in NI and their fragmentation pattern can be referred to in Andini et al. ${ }^{37}$ NACITCs have $\mathrm{UV}_{\max }$ at $268 \mathrm{~nm}$ and were detected in NI and PI modes. The diagnostic fragment ion for NAC-ITCs was $[\mathrm{NAC}-\mathrm{H}]^{-}(\mathrm{m} / z$ 162 , the most abundant $)$ in $\mathrm{NI}$ mode and $[\mathrm{NAC}+\mathrm{H}]^{+}(\mathrm{m} / z 164$, $>15 \%$ abundance) in PI mode. The quantification of GSLs and NAC-ITCs was based on the response in NI mode. The quantification of 3-(methylthio)propyl GSL (3-MTGSL), 5(methylsulfinyl)pentyl GSL (5-MSGSL), 2-hydroxy-4-pentenyl GSL (2-OH-PeGSL), 5-(methylsulfinyl)pentyl ITC (5-MSITC), and $p$ hydroxybenzyl ITC ( $p$-OH-BITC) (i.e., the compounds without standards) was performed by using the calibration equation of the standard GSL or ITC from the same subclass with the closest structural resemblance and molecular weight (Table S1).

Linearity of the Calibration Curves. Calibration series of 14 GSLs and 15 ITCs (i.e., NAC-ITCs) were prepared at concentrations of $2 \mu \mathrm{M}$ (for GSLs) or $3 \mu \mathrm{M}$ (for ITCs) to $60 \mu \mathrm{M}$. The calibration curves, consisting of eight data points, were obtained by plotting concentration versus NI-MS chromatographic peak area of the analyte at $\mathrm{m} / z$ of its molecular ion. The linearity of the calibration curves was indicated by the coefficient of determination $\left(R^{2}\right)$.

Limits of Detection and Quantification. The LOD was determined from the calibration curves. ${ }^{38}$ The LOD is the smallest concentration of analyte in the test sample that can be reliably distinguished from zero. ${ }^{39}$ The root mean square error (RMSE) approach was applied to calculate the LOD. According to Bernal \& Guo, ${ }^{38}$ this approach uses both the variability of the blank and of the measurement values. The following formulas were used to calculate the LOD

$$
\begin{aligned}
& \mathrm{LOD}=\frac{3.3 \mathrm{RMSE}}{a} \\
& \mathrm{RMSE}=\left(\frac{\sum_{i=1}^{n}(y-y(x))^{2}}{n-2}\right)^{0.5}
\end{aligned}
$$

where RMSE is the residual standard deviation of the calibration curve, $a$ is the slope of the calibration curve, $y$ is the measured peak area, $y(x)$ is the theoretical peak area calculated from the calibration equation, and $n$ is the number of regression points. The LOD should meet the following two requirements: (i) LOD $<C_{\min }$ and (ii) $10 \times$ LOD $>C_{\min }$. The LOQ was calculated according to Pilipczuk et al. and FDA. ${ }^{31,40}$

$$
\text { LOQ }=3 \times \text { LOD }
$$

Precision. For the standard mixtures of 14 GSLs and 15 ITCs, the intraday precision was determined by replicate analysis $(n=3)$ at five concentrations ranging from 5 to $50 \mu \mathrm{M}$ in one day. The interday precision was determined by replicate analysis in three separate days $(n=3)$. The standard mixtures were subjected to the NACderivatization. The intra- and interday precisions for the standard mixtures were expressed as a percentage of overall relative standard deviation (\% RSD) of the NI-MS chromatographic peak areas of the analytes. The overall precisions (\% RSD) were calculated using eq 4, where $\mathrm{RSD}_{i}(\%)$ is RSD (i.e., coefficient of variation, CV) for the $i$-th concentration point, and $n$ is the number of calibration points. ${ }^{31}$

For the spiked extracts of $S$. alba, B. napus, and B. juncea, the intraand interday precisions were determined simultaneously: two replicates in day 1 and another two replicates in day 2 . The extracts were spiked with a mixture of 14 GSLs and 15 ITCs (each analyte at $30 \mu \mathrm{M}$ ). The spiked extracts were subjected to the NACderivatization. The intra- and interday precisions for the spiked extracts were expressed as percentage of overall relative standard deviation (\% RSD) of the concentrations of the spiked analytes and evaluated simultaneously by one-way ANOVA. ${ }^{40,41}$

$$
\mathrm{RSD}=\sqrt{\frac{1}{n} \sum_{i=1}^{n} \mathrm{RSD}_{i}^{2}}
$$

Recovery. To further evaluate the applicability of the method for analyzing extracts, recovery was determined by analyzing the three different Brassicaceae seed extracts (i.e. S. alba, B. napus, and B. juncea), spiked with 14 GSL and 15 ITC standards (each at two levels: 10 and $30 \mu \mathrm{M}$ ), derivatized with NAC. Recovery (\%) was calculated as

$$
R(\%)=\frac{x_{\text {spiked }}-x_{\text {unspiked }}}{x_{\text {ref }}} \times 100
$$

where $x_{\text {spiked }}$ was the measured concentration of the analyte in the spiked experiment, $x_{\text {unspiked }}$ was the measured concentration of the 
analyte in the unspiked experiment, and $x_{\text {ref }}$ was the true concentration which was spiked to the extract. Four repetitions were performed.

According to FDA, ${ }^{40}$ a good recovery for the working analyte concentrations in this study should be between 80 and $110 \%$. To test whether the recovery was within the range, the recovery whose average outside the range was statistically evaluated by analysis of variance (ANOVA) one-sample $t$-test using IBM SPSS Statistic v.23 software (SPSS Inc., Chicago, IL, U.S.A.).

\section{RESULTS AND DISCUSSION}

Development of RP-UHPLC-PDA-ESI-MS ${ }^{n}$ Method for GSL and ITC Analysis. Simultaneous quantitative analysis of different GSLs and ITCs was performed using RP-UHPLCPDA-ESI-MS ${ }^{\mathrm{n}}$. The method included derivatization of ITCs with NAC, which was based on the method developed by Pilipczuk et al., ${ }^{31}$ enabling detection of ITCs in MS. The method of Pilipczuk et al. ${ }^{31}$ was modified to also enable analysis of very polar GSLs.

To ensure a good separation of the very polar GSLs, two important parameters were optimized. First was the column oven temperature as it influences the elution; the lower the temperature, the more delay in elution, which benefits the separation of polar compounds. Three different column oven temperatures, i.e. 25,35 , and $45{ }^{\circ} \mathrm{C}$, were tested. At column oven temperature of $25^{\circ} \mathrm{C}$, sharp peaks were obtained and the seven most polar GSLs (G1, G6, G13, G11, G2, G5, and G16), which were eluted within $5 \mathrm{~min}$, were separated (Figure 2A). Column oven temperature of $25{ }^{\circ} \mathrm{C}$ was also applied in previous research analyzing intact GSLs by LC-ESI-MS. ${ }^{24}$ In contrast, higher column oven temperatures, which were 35 and $45{ }^{\circ} \mathrm{C}$, resulted in poor separation for these seven most polar GSLs (data not shown). Column oven temperatures lower than $25^{\circ} \mathrm{C}$ might improve the separation, but as this would extend the analysis time and cause high backpressure, this was not further elaborated.

Second, the polarity of the solvent is important for analyzing both GSLs and NAC-ITCs. All GSLs are soluble in water, but not all NAC-ITCs are soluble in water. IPA has been found to be better than methanol and ethanol to dissolve ITCs. ${ }^{31}$ Furthermore, to dissolve both GSLs and ITCs in one mixture, $25 \%(\mathrm{v} / \mathrm{v})$ aqueous IPA was found to be a better solvent than IPA 50\%. This was indicated by the elution profiles of representative GSLs and ITCs in both solvents shown in Figure S1 (B, D vs C, E).

Figure 2A shows a good baseline separation of 15 NACITC peaks (retention time, tR, of $17-40 \mathrm{~min}$ ) in IPA $25 \%$. Because quantification was based on the MS signal, coelution (e.g., I4 and I15) and partial peak overlap (e.g., G15 and G8) did not affect the quantification, as the compounds have different $\mathrm{m} / z$.

Linearity of the Calibration Curves. The results of the regression analysis of 14 GSLs and 15 ITCs are listed in Table 2. Statistical analysis of the calibration data of GSL $(2-60 \mu \mathrm{M})$ and ITC $(3-60 \mu \mathrm{M})$ showed a high linearity $\left(R^{2} \geq 0.994\right)$.

Limits of Detection and Quantification. All LOD and LOQ values are presented in Table 2. The LOD values for GSLs and ITCs were within a range of $0.4-2.6 \mu \mathrm{M}$. With regard to GSL analysis, our LC-MS method has higher sensitivity than the method with CE-MEKC-UV (LOD up to $30 \mu \mathrm{M}),{ }^{36}$ and this is in line with a previous study using the LC-MS method. ${ }^{34}$ With regard to NAC-ITCs, our analytical protocol generated lower LOD values than those obtained by Pilipczuk et al. ${ }^{31}(1.7-4.9 \mu \mathrm{M})$. The LOQ values of our
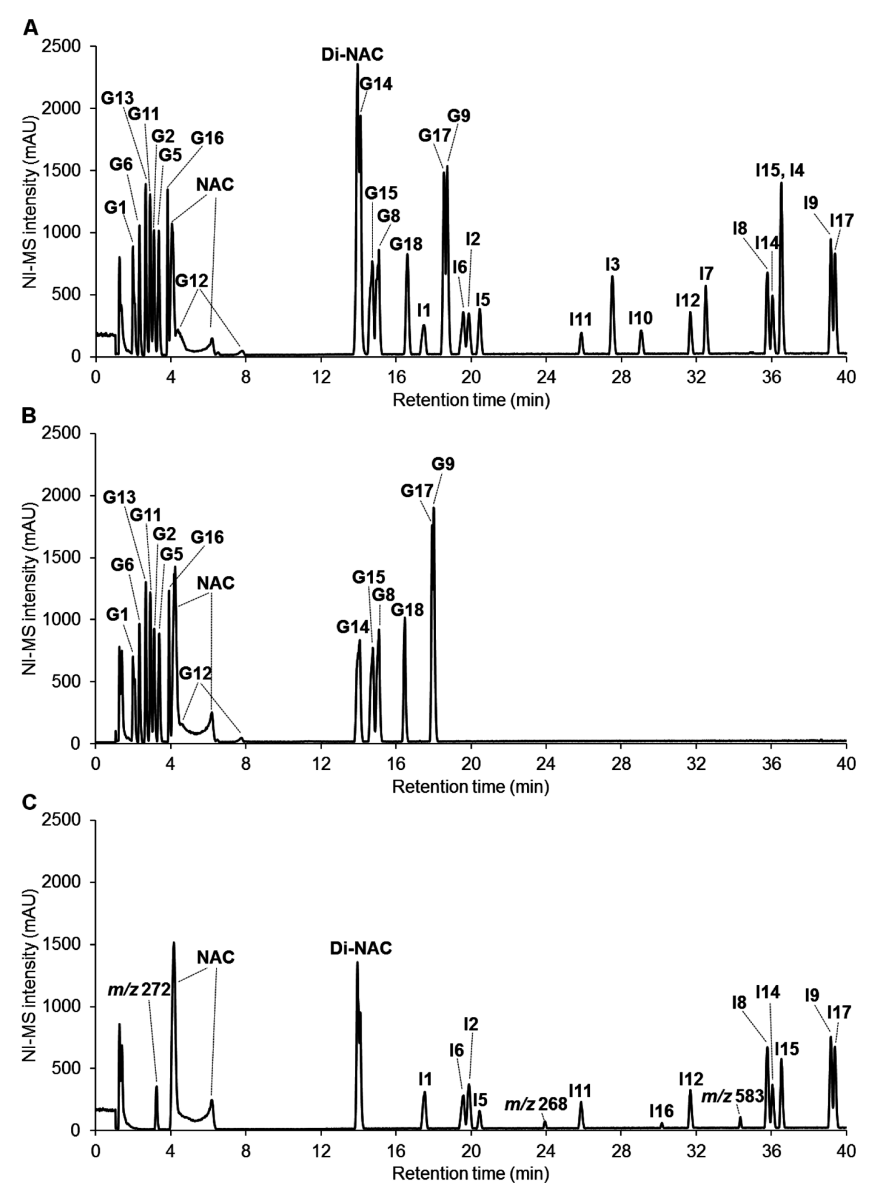

Figure 2. UHPLC-MS negative ion chromatograms of a mixture of 14 different GSLs (each $30 \mu \mathrm{M}$ ) and 15 different ITCs (each $30 \mu \mathrm{M}$ ) derivatized with NAC $(2.25 \mathrm{mM})$ in $25 \%(\mathrm{v} / \mathrm{v})$ aqueous IPA at $50{ }^{\circ} \mathrm{C}$ for $2 \mathrm{~h}(\mathrm{~A})$; a mixture of $14 \mathrm{GSLs}$ (each at $30 \mu \mathrm{M}$ ), myrosinase, and NAC upon incubation at $50{ }^{\circ} \mathrm{C}$ at $0 \mathrm{~h}$ (B) and $4 \mathrm{~h}$ (C). The chromatograms refers to base peak chromatograms. The analyses were performed at a column oven temperature of $25^{\circ} \mathrm{C}$. G12 and NAC each appeared in two peaks, but the identification and quantification of the GSL were still feasible. The elution was depending on the solvent; in the absence of organic solvent, they were eluted as one peak (Figure S3).

method for GSLs and ITCs were within a range of 1.2-7.8 $\mu \mathrm{M}$. Overall, our new analytical method can be applied for quantification of GSLs and NAC-ITCs at low concentrations.

Precision. The intraday and interday precisions of the developed method are displayed in Table 2. For the analyte concentration applied in our study, good intraday and interday precisions should be $\leq 10 \% \mathrm{RSD}$ and $16 \% \mathrm{RSD}$, respectively. ${ }^{40}$

For GSL analysis in the standard mixtures, the intra- and interday precisions of the method for all GSLs $(\leq 8.9 \% \mathrm{RSD}$ and $\leq 14.8 \%$ RSD, respectively) complied with the FDA requirement.

For GSL analysis in the spiked extracts, the intraday and interday precisions of most GSLs (0.6-10.0\% RSD and 2.0$16.0 \%$ RSD, respectively) were within the permitted FDA range. PeGSL (G14) and $p$-OH-BGSL (G16) had lower intraand interday precisions than the other GSLs in the three spiked extracts.

For NAC-ITC analysis in the standard mixtures, the intraand interday precisions of the method (7.2-10.0\% RSD and 10.8-16.0\% RSD, respectively) complied with the FDA 


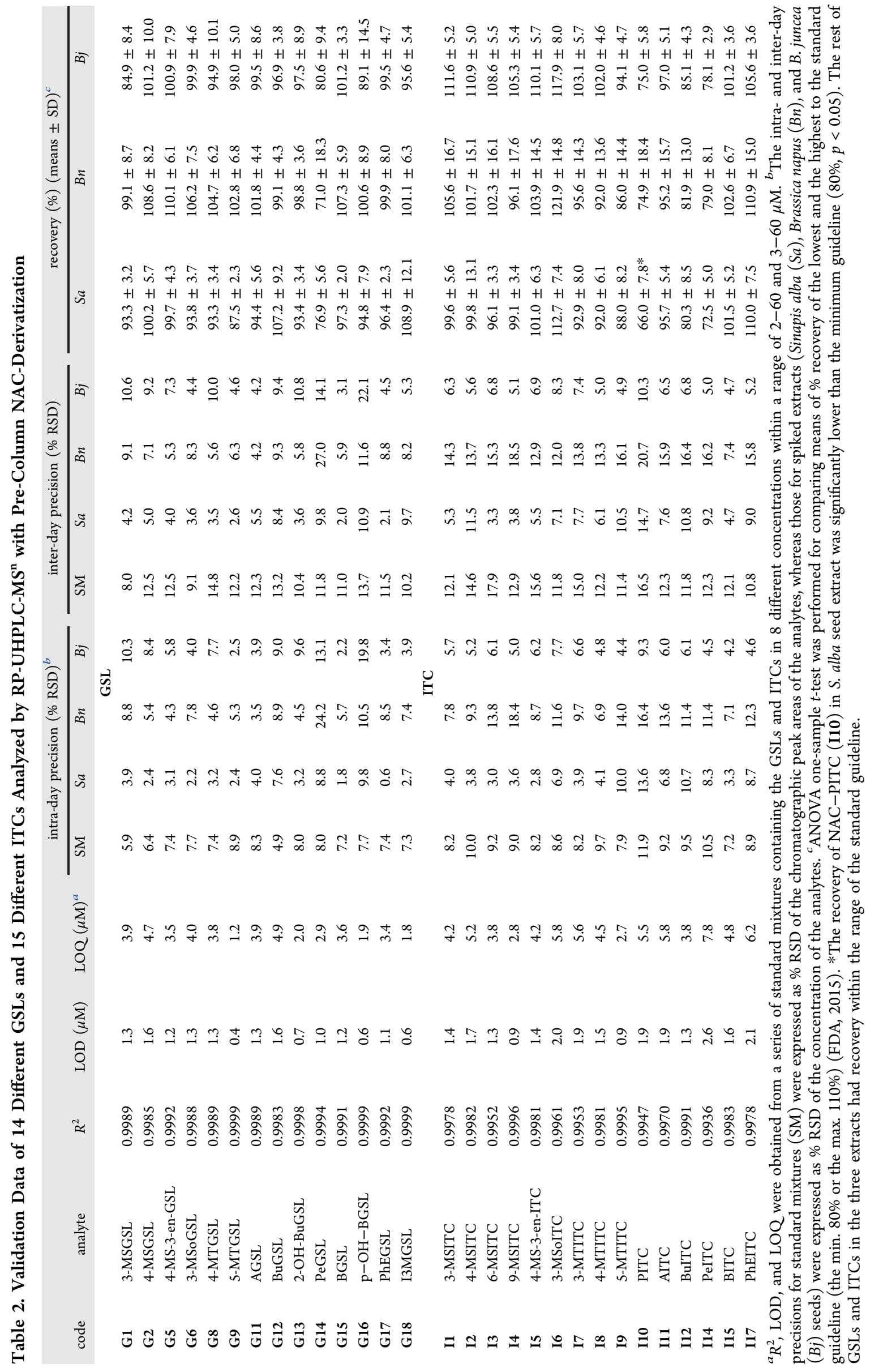


requirement for most ITCs. Only two ITCs had a slightly lower intra- and interday precision (up to $11.9 \% \mathrm{RSD}$ and $17.9 \%$ RSD, respectively). The intraday precision of nine NAC-ITCs in a previous study was higher $(1.8-5.0 \%$ RSD). ${ }^{31}$ In our study, the calibration series of NAC-ITCs was made from the NAC-derivatization of the authentic standards of ITCs, and not from the purified or authentic standard NAC-ITCs as in Pilipczuk et al. ${ }^{31}$ Therefore, the intraday precision obtained in our study reflected the variation not only of the actual LC-MS analysis, but also of the NACderivatization process.

For NAC-ITC analysis in the spiked extracts, the intraday precisions of the method tended to vary among extracts rather than among analytes. NAC-ITC analysis in the spiked S. alba and B. juncea extracts had intra- $(2.8-10.0 \% \mathrm{RSD})$ and interday precisions $(3.3-14.7 \%$ RSD) within the FDA requirement, except for the intraday precision of $\mathbf{I 1 0}$ and $\mathbf{I 1 2}$ in $S$. alba extract (up to $13.6 \% \mathrm{RSD}$ ). However, the analysis of 9 of 15 NAC-ITCs in the spiked B. napus extract had lower intraday precision (11.4-18.4\% RSD) than the FDA requirement. This might be due to the presence of other lowmolecular-weight thiol compounds (such as glutathione (GSH), the dominant thiol compound in most plant cells $^{42,43}$ ) in the extract, which might compete with NAC in reacting with ITCs. Nevertheless, this competition was not expected in our study, because GSL extraction was done in absolute methanol where GSH is insoluble. ${ }^{44}$ When the extraction is done in aqueous solvent, coextracting GSH, the level of this thiol compound in the extract should be considered. Despite this relatively low intraday precision of NAC-ITCs in the spiked B. napus extract, the interday precision of the majority (10 NAC-ITCs) complied with the FDA.

Recovery. The recovery of 14 GSLs and 15 NAC-ITCs spiked in S. alba, B. napus, and B. juncea extracts was evaluated. Two concentration levels were applied, which were 10 and 30 $\mu \mathrm{M}$. The chromatograms of $B$. napus extracts, as a representative, are shown in Figure S4. All GSLs and ITCs added to the extract were distinguishable, and their intensity increased upon increasing concentration, except for G12 and G13 as they were constitutively present in high abundance (>80 $\mu \mathrm{M}$, outside the range of concentrations used for calibration).

The recovery is the closeness of agreement between the true value of the analyte concentration and the experimental result. $^{40,41}$ According to $\mathrm{FDA}^{40}$ a good recovery for our working analyte concentrations should be between 80 and $110 \%$.

The recoveries for GSLs ranged from $71 \pm 18$ to $110 \pm 6 \%$ (Table 2), complying with the FDA requirement $(p>0.05)$. PeGSL (G14) had a tendency to have a lower recovery than the other 13 GSLs in all the three spiked extracts.

The recoveries of NAC-ITCs ranged from $66 \pm 8$ to $122 \pm$ $15 \%$ (Table 2). NAC-PITC (I10) had a tendency to have a lower recovery, whereas NAC-3-MSoITC (I6) had a tendency to have a higher recovery than the other 14 NAC-ITCs in all three spiked extracts. Only NAC-PITC (I10) in S. alba extract had a recovery lower than the minimum FDA requirement $(80 \%, p<0.05)$. Pilipczuk et al. ${ }^{31}$ found satisfactory recoveries (83-104\%) for nine NAC-ITCs, including NAC-methyl ITC and NAC-ethyl ITC (shorterchained analogues of PITC). Considering ITC's physicochem- ical properties, for example, boiling point and reactivity, we found no plausible explanation for the low recovery of PITC.

Overall, our method is well suited to quantify various GSLs and ITCs (as NAC-ITCs) in complex mixtures, such as plant extracts, with a high precision and recovery for most analytes. The method also offers an alternative way of making calibration series of NAC-ITCs, which is from the fresh NAC-derivatization of standard ITCs.

Detection of Various Enzymatic Hydrolysis Products of GSLs. At neutral conditions, most GSLs are degraded to form ITCs upon myrosinase treatment. ${ }^{4-6}$ Our new analytical method was applied to monitor simultaneously the decrease of the concentration of 14 different standard GSLs and the increase of the concentration of their corresponding ITCs, in the form of NAC derivatives, during enzymatic hydrolysis. In our study, ITCs were the default rearrangement products of the aglucones (Figure 1) in the GSL extracts treated with the commercial myrosinase, supporting previous studies. ${ }^{45,46}$ Figure $2 \mathrm{~B}$ shows the presence of 14 GSLs before hydrolysis with myrosinase. Figure $2 \mathrm{C}$ indicates that after incubation with myrosinase and NAC at $50{ }^{\circ} \mathrm{C}$ for $4 \mathrm{~h}$, all $14 \mathrm{GSL}$ were hydrolyzed, peaks corresponding to 12 NAC-ITCs and 3 unknown peaks appeared.

Upon myrosinase treatment 2-hydroxylated alkenyl GSLs and indolic GSLs form unstable ITCs which further form other types of products. ${ }^{13,47}(R)-2-\mathrm{OH}-\mathrm{BuGSL}$ or progoitrin (G13) is known to form unstable 2-OH-3-butenyl ITC, which spontaneously cyclizes forming 5-ethenyl-1,3-oxazolidine-2thione (i.e., goitrin) ${ }^{47}$ (Figure S5A). However, the reaction product of a mixture of G13, myrosinase, and NAC is unknown in literature. Therefore, it remains unclear whether goitrin or the unstable 2-OH-3-butenyl ITC had reacted with NAC (Figure S5B,C), which might depend on the rates of cyclization of the ITC and of reaction between the ITC and NAC. In addition, the reaction product between goitrin and NAC has never been described in literature. A peak at a tR of $34.3 \mathrm{~min}$ and $\mathrm{m} / \mathrm{z}$ of 583 (Figure 2C) might correspond to a dimer of reaction product between NAC and the hydrolysis product of G13 with a molecular formula of $\mathrm{C}_{20} \mathrm{H}_{32} \mathrm{~N}_{4} \mathrm{O}_{8} \mathrm{~S}_{4}$ (584 Da) (Figure S5D). The fragmentation gave an ion at $\mathrm{m} / z$ of 291 (possibly the monomer) at the most abundant, and this was fragmented to an ion at $\mathrm{m} / z$ of 162 (possibly the NAC). Meanwhile, indol-3ylmethyl (I3M) GSL (G18) forms various hydrolysis products, for example, indole-3-acetonitrile and I3M ITC, which further reacts with water to form indole-3carbinol. ${ }^{13,48,49}$ However, these compounds and their possible reaction products with NAC were not detected in our LC-MS analysis.

Furthermore, Figure $2 \mathrm{C}$ indicates two other peaks at 3.25 $\min (\mathrm{m} / z 272)$ and $23.94 \mathrm{~min}(\mathrm{~m} / z 268)$, which were related to G5 and G16, which were GSLs partially converted to their corresponding ITCs (I5 and I16) (Table 3). The presence of the first peak was never indicated previously, and the annotation requires structural elucidation by NMR spectroscopy. A previous study found that G5 was hydrolyzed to form I5, which was unstable and rapidly converted to a watersoluble degradation product, namely 6-[(methylsulfinyl)methyl]-1,3-thiazinan-2-thione, at $25{ }^{\circ} \mathrm{C}, \mathrm{pH} 7 .^{50}$ However, this compound was not detected in our LC-MS analysis. The second peak was tentatively annotated as $\mathrm{C}_{12} \mathrm{H}_{15} \mathrm{NO}_{4} \mathrm{~S}(269$ $\mathrm{Da})$, which was possibly an ester from $p$-OH-benzyl alcohol and NAC (Figure S6), and observed after 3-h incubation. G16 formed not only I16 ( $13 \%$ conversion, Table 3 ), but also $p$ - 
Table 3. Rates $(\mu \mathrm{M} / \mathrm{h})$ of Enzymatic Hydrolysis of GSLs and Formation of NAC-ITCs from ITCs Released upon Hydrolysis and Simultaneous NAC-Derivatization, and Conversion of GSLs to ITCs

\begin{tabular}{|c|c|c|c|c|c|c|}
\hline \multirow[b]{2}{*}{$\begin{array}{l}\text { GSL or } \\
\text { ITC }\end{array}$} & \multirow[b]{2}{*}{ R-group ${ }^{a}$} & \multicolumn{2}{|c|}{$\begin{array}{c}\text { hydrolysis of } \\
\text { GSL }\end{array}$} & \multicolumn{3}{|c|}{ formation of NAC-ITC } \\
\hline & & rate & $R^{2}$ & rate & $R^{2}$ & $\begin{array}{c}\text { conversion } \\
(\%)\end{array}$ \\
\hline \multicolumn{7}{|c|}{ subclass (methylsulfinyl)alkyl (MS) } \\
\hline G1, I1 & 3-MS & 13.6 & 0.981 & 11.7 & 0.968 & 100 \\
\hline G2, I2 & 4-MS & 11.2 & 0.987 & 10.7 & 0.922 & 100 \\
\hline \multicolumn{7}{|c|}{ subclass (methylsulfinyl)alkenyl (MS-en) } \\
\hline G5, I5 & 4-MS-3-en & 11.9 & 0.986 & 7.4 & 0.945 & 63 \\
\hline \multicolumn{7}{|c|}{ subclass (methylsulfonyl)alkyl (MSo) } \\
\hline G6, I6 & 3-MSo & 17.3 & 0.966 & 10.4 & 0.965 & 100 \\
\hline \multicolumn{7}{|c|}{ subclass (methylthio)alkyl (MT) } \\
\hline G8, I8 & 4-MT & 18.4 & 0.982 & 10.1 & 0.952 & 100 \\
\hline G9, I9 & 5-MT & 19.7 & 0.991 & 9.7 & 0.968 & 100 \\
\hline \multicolumn{7}{|c|}{ subclass alkenyl } \\
\hline G11, I11 & A & 20.6 & 0.990 & 11.1 & 0.959 & 100 \\
\hline G12, I12 & $\mathrm{Bu}$ & 25.4 & 0.994 & 9.0 & 0.866 & 100 \\
\hline G13, n.a. & $2-\mathrm{OH}-\mathrm{Bu}$ & 28.4 & 0.999 & n.a. ${ }^{b}$ & n.a. & n.a. \\
\hline G14, I14 & $\mathrm{Pe}$ & 20.3 & 0.966 & 9.3 & 0.870 & 100 \\
\hline \multicolumn{7}{|c|}{ subclass benzenic } \\
\hline G15, I15 & $\mathrm{B}$ & 26.9 & 0.989 & 9.1 & 0.809 & 100 \\
\hline G16, I16 & $p$-OH-B & 29.7 & 0.959 & n.d. ${ }^{c}$ & n.d. & 13 \\
\hline G17, I17 & $\mathrm{PhE}$ & 20.8 & 0.985 & 11.0 & 0.919 & 100 \\
\hline \multicolumn{7}{|c|}{ subclass indolic } \\
\hline G18, n.a. & $\mathrm{I} 3 \mathrm{M}$ & 25.7 & 0.983 & n.a. & n.a. & n.a. \\
\hline
\end{tabular}

${ }^{a} \mathrm{R}$-groups are presented in the abbreviations, referring to Table 1 .

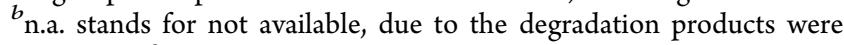
not ITCs. ${ }^{c}$ n.d. indicates that the concentration of the compound cannot be determined due to lack of standard. Therefore, the conversion (13\%) was calculated by taking the concentration BITC equivalent for this $p$-OH-BITC.

OH-benzyl alcohol, which is in line with the finding of Buskov et al., confirming the structure by NMR spectroscopy. ${ }^{51}$

Overall, our results underline that the amount of ITCs formed upon hydrolysis of GSLs does not necessarily equal that of hydrolyzed GSLs, and this is influenced by the side chain. Therefore, the amount of ITCs formed upon hydrolysis of GSLs should be determined appropriately.

Quantitative Monitoring of the Enzymatic Conversion of Standard GSLs to NAC-ITCs. Figure 3A (no organic solvent) and 3B (25\% IPA) demonstrate the progress of hydrolysis of an aliphatic GSL (G1) and an aromatic GSL (G15), as representatives, and the progress of NACderivatization of the corresponding ITCs (I1 and I15). The graphs for the other GSLs and NAC-ITCs are displayed in Figure S7. In general, the hydrolysis of all GSLs at $50{ }^{\circ} \mathrm{C}, \mathrm{pH}$ 7.0 , occurred to completion at $1.5-2.5 \mathrm{~h}$, whereas the complete conversion to their respective NAC-ITCs lasted longer $(2.5-3.5 \mathrm{~h})$. Table 3 shows the rates of GSL hydrolysis and NAC-ITC formation for all tested compounds. The hydrolysis rates of the 14 GSLs were within $11.2-29.7 \mu \mathrm{M} / \mathrm{h}$. A previous study using the same commercial $S$. alba myrosinase, but different incubation temperature $\left(37{ }^{\circ} \mathrm{C}\right)$, found much higher hydrolysis rates $(369-800 \mu \mathrm{M} / \mathrm{h}) .^{35}$ The lower hydrolysis rates found in our study in comparison with this previous study ${ }^{35}$ were probably because we used a lower concentration of myrosinase $(0.05 \mathrm{U} / \mathrm{mL}$ vs $1.10-14.52 \mathrm{U} /$ $\mathrm{mL})$. The formation rates of NAC-ITCs were within 7.4-
11.7 $\mu \mathrm{M} / \mathrm{h}$. The slower rate of NAC-ITCs formation compared to GSL hydrolysis might be explained by the effect of solvent as the solubility of ITCs are favored in organic solvent. Figure $3 \mathrm{~B}$ indicates that when the hydrolysis of GSLs and the formation of NAC-ITCs co-occurred in IPA 25\%, the rates were comparable. However, the hydrolysis of 3-MSGSL in IPA $25 \%$ was not fully accomplished in $4 \mathrm{~h}$ (Figure 3B). Therefore, the rest of experiments on the simultaneous enzymatic hydrolysis of GSLs and NAC-ITC formation occurred in the absence of IPA.

Based on the hydrolysis rates (Table 3), the alkenyl, benzenic, and indolic GSLs were the most preferred substrates of myrosinase (hydrolysis rate of 20.3-29.7 $\mu \mathrm{M} / \mathrm{h}$ ), followed by (methylthio)alkyl and (methylsulfonyl)alkyl GSLs (17.319.7 $\mu \mathrm{M} / \mathrm{h})$. The least preferred substrates were (methylsulfinyl)alkyl and (methylsulfinyl)alkenyl GSLs $(11.2-13.6 \mu \mathrm{M} / \mathrm{h})$. In our study, the myrosinase used was originally isolated from $S$. alba seed. p-OH-BGSL (G16) is the most abundant GSL in this seed and had the highest hydrolysis rate $(29.7 \mu \mathrm{M} / \mathrm{h})$. Our finding supports previous studies, ${ }^{36,52}$ indicating that myrosinase acts more efficiently on the most abundant GSL present in the plant, to which both myrosinase and GSL belong.

Enzymatic Conversion of Constitutive GSLs to ITCs in Plant Extracts. To further test the applicability of our method, simultaneous enzymatic hydrolysis of GSLs and NACderivatization of ITCs was also performed in the three Brassicaceae seed extracts. The condition of this hydrolysis was similar to that of the hydrolysis of standard GSLs in our study $\left(50{ }^{\circ} \mathrm{C}\right.$, buffer $\left.\mathrm{pH} 7.0\right)$, except for the presence of DMSO $5 \%$ to assist the solubilization of the extracts. Under this condition, all GSLs were hydrolyzed completely within $4 \mathrm{~h}$ (similar to the experiments without DMSO; data not shown).

Figure $3 \mathrm{C}-\mathrm{E}$ indicates the concentration (in logarithmic scale) of GSLs in extracts of each species before hydrolysis and of NAC-ITCs after $4 \mathrm{~h}$ of hydrolysis. The predominant GSLs in S. alba, B. napus, and B. juncea seed extracts at $5 \mathrm{mg} / \mathrm{mL}$ were $p$-OH-BGSL (G16) $1857 \mu \mathrm{M}, 2-\mathrm{OH}-\mathrm{BuGSL}$ (G13) 128 $\mu \mathrm{M}$, and BuGSL (G12) $2012 \mu \mathrm{M}$, respectively, which equaled 61,4 , and $66 \mu \mathrm{mol} / \mathrm{g}$ DW seed, respectively. The result was in agreement with a previous study. ${ }^{37}$

For GSLs which form only ITCs upon myrosinase treatment in neutral $\mathrm{pH}$ solution, for example, 3-MSGSL (G1), 4MTGSL (G8), AGSL (G11), and BuGSL (G12), the concentration of ITCs formed was comparable to that of the corresponding GSLs (Figure 3C-E), consistent with our results from the hydrolysis of standard GSLs (Figures $3 \mathrm{~A}$ and S7). $p$-OH-BGSL (G16) partially formed ITC (Figure 3C), two hydroxylated alkenyl GSLs (i.e., 2-OH-BuGSL G13, 2OH-PeGSL G20) and I3M GSL (G18) formed no ITC (Figure $3 \mathrm{C}-\mathrm{E}$ ), in accordance with the findings obtained in the hydrolysis of standard GSLs (section Detection of Various Enzymatic Hydrolysis Products of GSLs).

Our method enabled analysis of plant extracts with different GSL and ITC compositions. If the plant extract would contain excessive amounts of ITC, then the amount of NAC for derivatization might become limiting. In such a case, several dilutions of the plant extract should be prepared, while keeping the concentration of NAC constant, for example, $2.25 \mathrm{mM}$ (as applied in the spike experiments), to confirm that the amount of NAC is sufficient to react with all ITCs.

Several methods to analyze GSLs and ITCs simultaneously were developed previously, ${ }^{33-36}$ some of which were with high 


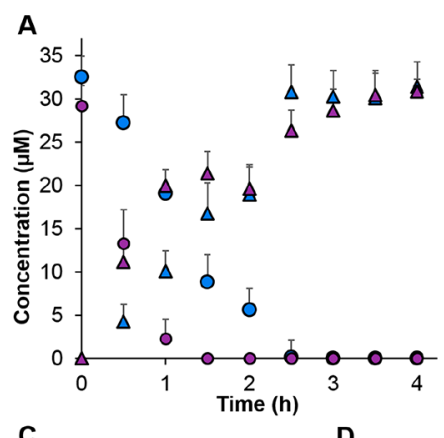

C

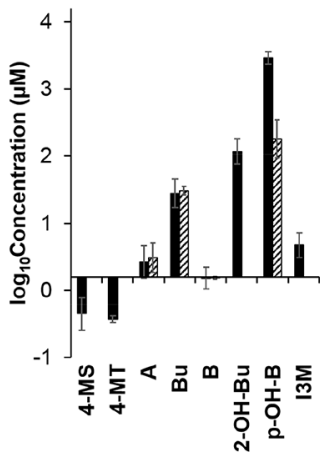

B

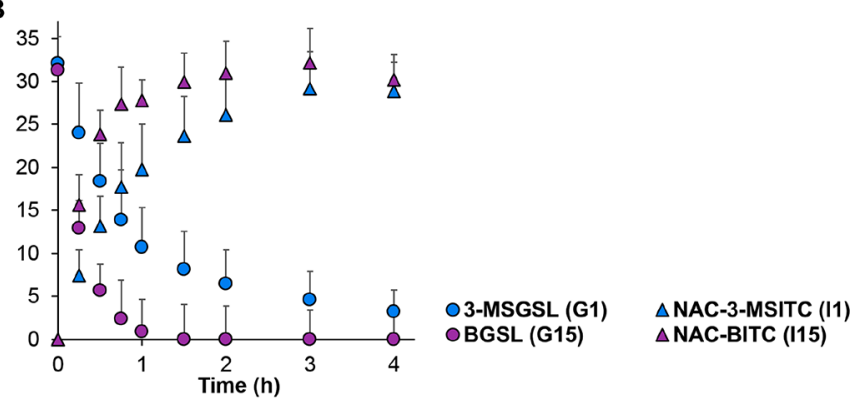

E

D

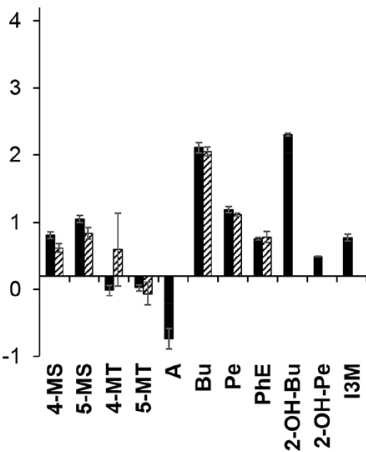

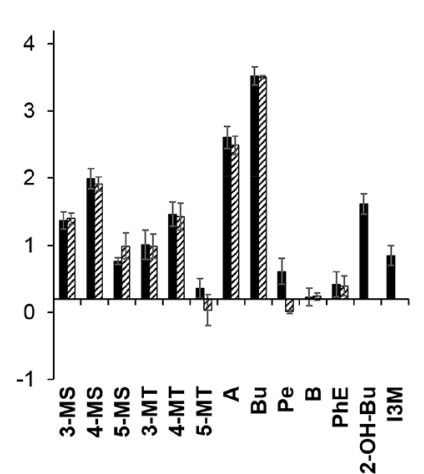

Figure 3. Simultaneous enzymatic hydrolysis of GSLs and NAC-derivatization of ITCs that were released: the decrease in concentration of GSLs (circles) and the increase in concentration of NAC-ITCs (triangles) during enzymatic hydrolysis of standard GSLs in the absence of organic solvent (A), in IPA 25\% (B); concentration (in logarithmic scale) of constitutive GSLs (filled bars) before hydrolysis and their corresponding ITCs (hatched bars) in S. alba (C), B. napus (D), and B. juncea (E) seed extracts $\left(5 \mathrm{mg} / \mathrm{mL}\right.$ ) after 4 h hydrolysis at $50{ }^{\circ} \mathrm{C}$. Hydroxylated aliphatic GSLs (2-OH-BuGSL and 2-OH-PeGSL) and indole GSL (I3MGSL) did not form ITCs upon myrosinase treatment. $p$-OH-BITC was not the only hydrolysis product of $p$-OH-BGSL (G16). The error bars are the standard deviations for the means, taken from three independent experiments.

sensitivity and precision. ${ }^{34,36}$ In our study, we have developed an RP-UHPLC-ESI-MS ${ }^{\mathrm{n}}$ method able to analyze: (i) a more extensive set of GSLs and ITCs simultaneously comprising eight different subclasses, most of them with representatives of different chain lengths; (ii) complex mixtures, for example, plant extracts, by MS detection (more specific than UV detection); (iii) GSLs and ITCs directly after hydrolysis and NAC-derivatization, that is, simultaneous hydrolysis and analysis. Overall, this method is valuable for understanding the in vitro enzymatic conversion of GSLs to ITCs under various conditions.

\section{ASSOCIATED CONTENT}

\section{SI Supporting Information}

The Supporting Information is available free of charge at https://pubs.acs.org/doi/10.1021/acs.jafc.9b07920.

Base peak negative ion UHPLC-MS chromatograms of representative GSLs and ITCs in different solvents; base peak negative ion UHPLC-MS chromatograms of NAC-ITCs; base peak negative ion UHPLC-MS chromatograms of NAC in the absence of an organic solvent; base peak negative ion UHPLC-MS chromatograms of extracts of $B$. napus seeds, nonspiked and spiked with standards of 14 GSLs and 15 ITCs at different concentrations; hydrolysis schemes of (R)-2$\mathrm{OH}$-3-butenyl GSL and p-OH-benzyl GSL; decrease in concentration of GSLs and increase in concentration of ITCs; and GSLs and NAC-ITCs whose calibration curves were employed to quantify analytes (PDF)

\section{AUTHOR INFORMATION}

\section{Corresponding Author}

Jean-Paul Vincken - Laboratory of Food Chemistry, Wageningen University, 6700 AA Wageningen, The Netherlands; 10 orcid.org/0000-0001-8540-4327;

Phone: +31 317 482234; Email: jean-paul.vincken@wur.nl

\section{Authors}

Silvia Andini - Laboratory of Food Chemistry, Wageningen University, 6700 AA Wageningen, The Netherlands; Department of Chemistry, Satya Wacana Christian University, Salatiga 50711, Indonesia

Carla Araya-Cloutier - Laboratory of Food Chemistry, Wageningen University, 6700 AA Wageningen, The Netherlands

Mark Sanders - Laboratory of Food Chemistry, Wageningen University, 6700 AA Wageningen, The Netherlands

Complete contact information is available at:

https://pubs.acs.org/10.1021/acs.jafc.9b07920

\section{Funding}

The authors are grateful to Indonesia Endowment Fund for Education (LPDP), Ministry of Finance of Republic Indonesia, for the financial support for S.A. during her PhD study.

\section{Notes}

The authors declare no competing financial interest.

\section{ACKNOWLEDGMENTS}

The authors are thankful to Sjoera Tjin A-Lim for her help in the preliminary experiments of the enzymatic hydrolysis of GSLs, and to Roelant Hilgers for discussion on the organic chemistry reactions between goitrin and NAC. 


\section{REFERENCES}

(1) Ahuja, I.; Rohloff, J.; Bones, A. M. Defence mechanisms of Brassicaceae: implications for plant-insect interactions and potential for integrated pest management. A review. Agron. Sustainable Dev. 2010, 30, 311-348.

(2) Bones, A. M.; Rossiter, J. T. The myrosinase-glucosinolate system, its organisation and biochemistry. Physiol. Plant. 1996, 97, 194-208.

(3) Wittstock, U.; Kurzbach, E.; Herfurth, A. M.; Stauber, E. J.; Kopriva, S. Glucosinolate breakdown. Advances in Botanical Research; Academic Press, 2016; Vol. 80, Chapter 6, pp 125-169.

(4) Halkier, B. A.; Gershenzon, J. Biology and biochemistry of glucosinolates. Annu. Rev. Plant Biol. 2006, 57, 303-333.

(5) Matusheski, N. V.; Wallig, M. A.; Juvik, J. A.; Klein, B. P.; Kushad, M. M.; Jeffery, E. H. Preparative HPLC method for the purification of sulforaphane and sulforaphane nitrile from Brassica oleracea. J. Agric. Food Chem. 2001, 49, 1867-1872.

(6) Rosa, E. A. S.; Heaney, R. K.; Fenwick, G. R.; Portas, C. A. M. Glucosinolates in crop plants. Horticultural Reviews; Wiley, 1997.

(7) Calmes, B.; N’Guyen, G.; Dumur, J.; Brisach, C. A.; Campion, C.; Iacomi, B.; Pigne, S.; Dias, E.; Macherel, D.; Guillemette, T.; Simoneau, P. Glucosinolate-derived isothiocyanates impact mitochondrial function in fungal cells and elicit an oxidative stress response necessary for growth recovery. Front. Plant Sci. 2015, 6, 414.

(8) Aires, A.; Mota, V. R.; Saavedra, M. J.; Monteiro, A. A.; Simões, M.; Rosa, E. A. S.; Bennett, R. N. Initial in vitro evaluations of the antibacterial activities of glucosinolate enzymatic hydrolysis products against plant pathogenic bacteria. J. Appl. Microbiol. 2009, 106, 20962105.

(9) Dias, C.; Aires, A.; Saavedra, M. Antimicrobial activity of isothiocyanates from cruciferous plants against methicillin-resistant Staphylococcus aureus (MRSA). Int. J. Mol. Sci. 2014, 15, 1955219561.

(10) Turgis, M.; Han, J.; Caillet, S.; Lacroix, M. Antimicrobial activity of mustard essential oil against Escherichia coli O157:H7 and Salmonella typhi. Food Contr. 2009, 20, 1073-1079.

(11) Aires, A.; Mota, V. R.; Saavedra, M. J.; Rosa, E. A. S.; Bennett, R. N. The antimicrobial effects of glucosinolates and their respective enzymatic hydrolysis products on bacteria isolated from the human intestinal tract. J. Appl. Microbiol. 2009, 106, 2086-2095.

(12) Bones, A.; Rossiter, J. The enzymic and chemically induced decomposition of glucosinolates. Phytochemistry 2006, 67, 10531067.

(13) Agerbirk, N.; De Vos, M.; Kim, J. H.; Jander, G. Indole glucosinolate breakdown and its biological effects. Phytochem. Rev. 2008, 8, 101-120.

(14) Śmiechowska, A.; Bartoszek, A.; Namieśnik, J. Determination of glucosinolates and their decomposition products-indoles and isothiocyanates in cruciferous vegetables. Crit. Rev. Anal. Chem. 2010, 40, 202-216.

(15) Bennett, R. N.; Carvalho, R.; Mellon, F. A.; Eagles, J.; Rosa, E. A. S. Identification and quantification of glucosinolates in sprouts derived from seeds of wild Eruca sativa L. (salad rocket) and Diplotaxis tenuifolia L. (wild rocket) from diverse geographical locations. J. Agric. Food Chem. 2007, 55, 67-74.

(16) Bhandari, S.; Jo, J.; Lee, J. Comparison of glucosinolate profiles in different tissues of nine Brassica crops. Molecules 2015, 20, 1582715841.

(17) Kim, H. J.; Lee, M. J.; Jeong, M. H.; Kim, J. E. Identification and quantification of glucosinolates in kimchi by liquid chromatography-electrospray tandem mass spectrometry. Int. J. Anal. Chem. 2017, 2017, 6753481.

(18) Lee, M.-K.; Chun, J.-H.; Byeon, D. H.; Chung, S.-O.; Park, S. U.; Park, S.; Arasu, M. V.; Al-Dhabi, N. A.; Lim, Y.-P.; Kim, S.-J. Variation of glucosinolates in 62 varieties of Chinese cabbage (Brassica rapa L. ssp. pekinensis) and their antioxidant activity. LWT-Food Sci. Technol. 2014, 58, 93-101.
(19) Matthäus, B.; Luftmann, H. Glucosinolates in members of the family Brassicaceae: separation and identification by LC/ESI-MS-MS. J. Agric. Food Chem. 2000, 48, 2234-2239.

(20) Bennett, R. N.; Mellon, F. A.; Botting, N. P.; Eagles, J.; Rosa, E. A. S.; Williamson, G. Identification of the major glucosinolate (4mercaptobutyl glucosinolate) in leaves of Eruca sativa L. (salad rocket). Phytochemistry 2002, 61, 25-30.

(21) Förster, N.; Ulrichs, C.; Schreiner, M.; Müller, C. T.; Mewis, I. Development of a reliable extraction and quantification method for glucosinolates in Moringa oleifera. Food Chem. 2015, 166, 456-464.

(22) Wathelet, J. P.; Iori, R.; Leoni, O.; Rollin, P.; Quinsac, A.; Palmieri, S. Guidelines for glucosinolate analysis in green tissues used for biofumigation. Agroindustria 2004, 3, 257-266.

(23) Mellon, F. A.; Bennett, R. N.; Holst, B.; Williamson, G. Intact glucosinolate analysis in plant extracts by programmed cone voltage electrospray LC/MS: Performance and comparison with LC/MS/MS methods. Anal. Biochem. 2002, 306, 83-91.

(24) Millán, S.; Sampedro, M. C.; Gallejones, P.; Castellón, A.; Ibargoitia, M. L.; Goicolea, M. A.; Barrio, R. J. Identification and quantification of glucosinolates in rapeseed using liquid chromatography-ion trap mass spectrometry. Anal. Bioanal. Chem. 2009, 394, $1661-1669$.

(25) Song, L.; Morrison, J. J.; Botting, N. P.; Thornalley, P. J. Analysis of glucosinolates, isothiocyanates, and amine degradation products in vegetable extracts and blood plasma by LC-MS/MS. Anal. Biochem. 2005, 347, 234-243.

(26) Tian, Q.; Rosselot, R. A.; Schwartz, S. J. Quantitative determination of intact glucosinolates in broccoli, broccoli sprouts, Brussels sprouts, and cauliflower by high-performance liquid chromatography-electrospray ionization-tandem mass spectrometry. Anal. Biochem. 2005, 343, 93-99.

(27) Blažević, I.; Montaut, S.; Burčul, F.; Olsen, C. E.; Burow, M.; Rollin, P.; Agerbirk, N. Glucosinolate structural diversity, identification, chemical synthesis and metabolism in plants. Phytochemistry 2020, 169, 112100

(28) Chen, C.-W.; Ho, C.-T. Thermal degradation of allyl isothiocyanate in aqueous solution. J. Agric. Food Chem. 1998, 46, 220-223.

(29) Chiang, W. C. K.; Pusateri, D. J.; Leitz, R. E. A. Gas chromatography/mass spectrometry method for the determination of sulforaphane and sulforaphane nitrile in broccoli. J. Agric. Food Chem. 1998, 46, 1018-1021.

(30) Budnowski, J.; Hanschen, F. S.; Lehmann, C.; Haack, M.; Brigelius-Flohé, R.; Kroh, L. W.; Blaut, M.; Rohn, S.; Hanske, L. A derivatization method for the simultaneous detection of glucosinolates and isothiocyanates in biological samples. Anal. Biochem. 2013, 441, 199-207.

(31) Pilipczuk, T.; Kusznierewicz, B.; Chmiel, T.; Przychodzeń, W.; Bartoszek, A. Simultaneous determination of individual isothiocyanates in plant samples by HPLC-DAD-MS following SPE and derivatization with $N$-acetyl- $L$-cysteine. Food Chem. 2017, 214, 587596.

(32) Wilson, E. A.; Ennahar, S.; Zhao, M.; Bergaentzle, M.; Marchioni, E.; Bindler, F. Simultaneous determination of various isothiocyanates by RP-LC following precolumn derivatization with mercaptoethanol. Chromatographia 2011, 73, 137-142.

(33) Tsao, R.; Yu, Q.; Potter, J.; Chiba, M. Direct and simultaneous analysis of sinigrin and allyl isothiocyanate in mustard samples by high-performance liquid chromatography. J. Agric. Food Chem. 2002, 50, 4749-4753.

(34) Franco, P.; Spinozzi, S.; Pagnotta, E.; Lazzeri, L.; Ugolini, L.; Camborata, C.; Roda, A. Development of a liquid chromatographyelectrospray ionization-tandem mass spectrometry method for the simultaneous analysis of intact glucosinolates and isothiocyanates in Brassicaceae seeds and functional foods. J. Chromatogr. A 2016, 1428, $154-161$.

(35) Vastenhout, K. J.; Tornberg, R. H.; Johnson, A. L.; Amolins, M. W.; Mays, J. R. High-performance liquid chromatography-based 
method to evaluate kinetics of glucosinolate hydrolysis by Sinapis alba myrosinase. Anal. Biochem. 2014, 465, 105-113.

(36) Gonda, S.; Kiss-Szikszai, A.; Szűcs, Z.; Nguyen, N. M.; Vasas, G. Myrosinase compatible simultaneous determination of glucosinolates and allyl isothiocyanate by capillary electrophoresis micellar electrokinetic chromatography (CE-MEKC). Phytochem. Anal. 2016, 27, 191-198.

(37) Andini, S.; Dekker, P.; Gruppen, H.; Araya-Cloutier, C.; Vincken, J.-P. Modulation of glucosinolate composition in Brassicaceae seeds by germination and fungal elicitation. J. Agric. Food Chem. 2019, 67, 12770-12779.

(38) Bernal, E.; Guo, X. Limit of detection and limit of quantification determination in gas chromatography. Advances in Gas Chromatography; InTech: Rijeka, 2014; p Ch. 03.

(39) Currie, L. A. Nomenclature in evaluation of analytical methods including detection and quantification capabilities (IUPAC Recommendations 1995). Pure Appl. Chem. 1995, 67, 1699.

(40) FDA, Guidance for Industry. Studies to Evaluate the Metabolism and Residue Kinetics of Veterinary Drugs in FoodProducing Animals: Validation of Analytical Methods Used in Residue Depletion Studies. VICH GL49(R), Food and Drug Administration (FDA), Center for Veterinary Medicine; Department of Health and Human Services: Rockville, United States, 2015; p 23.

(41) Magnusson, B.; Örnemark, U. Eurachem Guide: The Fitness for Purpose of Analytical Methods-a Laboratory Guide to Method Validation and Related Topics, 2nd ed., 2014; p 70, www.eurachem. org.

(42) Anjum, N. A.; Umar, S.; Iqbal, M.; Ahmad, I.; Pereira, M. E.; Khan, N. A. Protection of growth and photosynthesis of Brassica juncea genotype with dual type sulfur transport system against sulfur deprivation by coordinate changes in the activities of sulfur metabolism enzymes and cysteine and glutathione production. Russ. J. Plant Physiol. 2011, 58, 892.

(43) Ruiz, J.; Blumwald, E. Salinity-induced glutathione synthesis in Brassica napus. Planta 2002, 214, 965-969.

(44) Haynes, W. M.; Lide, D. R.; Bruno, T. J. Handbook of Chemistry and Physics, 97th ed.; CRC Press Taylor and Francis Group: Boca Raton, 2016.

(45) Matusheski, N. V.; Juvik, J. A.; Jeffery, E. H. Heating decreases epithiospecifier protein activity and increases sulforaphane formation in broccoli. Phytochemistry 2004, 65, 1273-1281.

(46) Matusheski, N. V.; Swarup, R.; Juvik, J. A.; Mithen, R.; Bennett, M.; Jeffery, E. H. Epithiospecifier protein from broccoli (Brassica oleracea L. ssp. italica) inhibits formation of the anticancer agent sulforaphane. J. Agric. Food Chem. 2006, 54, 2069-2076.

(47) Greer, M. A. Isolation from rutabaga seed of progoitrin, the precursor of the naturally occurring antithyroid compound, goitrin (15-vinyl-2-thioöxazolidone). J. Am. Chem. Soc. 1956, 78, 1260-1261.

(48) Hauder, J.; Winkler, S.; Bub, A.; Rüfer, C. E.; Pignitter, M.; Somoza, V. LC-MS/MS quantification of sulforaphane and indole-3carbinol metabolites in human plasma and urine after dietary intake of selenium-fortified broccoli. J. Agric. Food Chem. 2011, 59, 8047-8057.

(49) McDanell, R.; McLean, A. E. M.; Hanley, A. B.; Heaney, R. K.; Fenwick, G. R. Chemical and biological properties of indole glucosinolates (glucobrassicins): A review. Food Chem. Toxicol. 1988, 26, 59-70.

(50) Song, D.; Liang, H.; Kuang, P.; Tang, P.; Hu, G.; Yuan, Q. Instability and structural change of 4-methylsulfinyl-3-butenyl isothiocyanate in the hydrolytic process. J. Agric. Food Chem. 2013, 61, 5097-5102.

(51) Buskov, S.; Hasselstrøm, J.; Olsen, C. E.; Sørensen, H.; Sørensen, J. C.; Sørensen, S. Supercritical fluid chromatography as a method of analysis for the determination of 4-hydroxybenzylglucosinolate degradation products. J. Biochem. Biophys. Methods 2000, 43, $157-174$.

(52) Román, J.; Castillo, A.; Cottet, L.; Mahn, A. Kinetic and structural study of broccoli myrosinase and its interaction with different glucosinolates. Food Chem. 2018, 254, 87-94. 